\title{
Factor Analysis for Metal Grade Exploration at Pallancata Vein in Peru
}

\author{
Jorge E. Gamarra-Urrunaga ${ }^{1}$, Ricardo Castroviejo ${ }^{2}$, and Jesús Domínguez ${ }^{2}$ \\ ${ }^{1}$ International Minerals Corporation, 230 South Rock Blvd, Reno, Nevada 89502, \\ USA, jgamarraurrunaga@yahoo.com. ${ }^{2}$ Universidad Politécnica de Madrid, ETSI Minas, \\ c/ Ríos Rosas, 21 (28003-Madrid, Spain), ricardo.castroviejo@upm.es; \\ jesus.dominguezR@upm.es
}

\begin{abstract}
The metal distribution in a vein may show the paths of hydrothermal fluid flow at the time of mineralization. Such information may assist for in-fill drilling. The Pallancata Vein has been intersected by 52 drill holes, whose cores were sampled and analysed, and the results plotted to examine the mineralisation trends. The spatial distribution of the ore is observed from the $\log \mathrm{Ag} / \log \mathrm{Pb}$ ratio distribution. Au is in this case closely related to $\mathrm{Ag}$ (electrum and uytenbogaardtite, $\mathrm{Ag}_{3} \mathrm{AuS}_{2}$ ). The $\mathrm{Au}$ grade shows the same spatial distribution as the $\mathrm{Ag}$ grade. The $\log \mathrm{Ag} / \log \mathrm{Pb}$ ratio distribution also suggests possible ore to be expected at deeper locations. Shallow supergene Ag enrichment was also observed.
\end{abstract}

Keywords: Pallancata Vein, Metal Ratio Exploration, Epithermal, Silver (Gold), Peru.

\section{Introduction}

The epithermal Pallancata Vein is located $~ 520 \mathrm{~km} \mathrm{SE}$ of Lima (Ayacucho department), at $\sim 200$ MASL. It crops out along $1.5 \mathrm{~km}$, with $\mathrm{N} 70^{\circ} \mathrm{W}$ strike and has a subvertical dip. Vein thicknesses are structurally controlled, both horizontally and vertically, varying from $1 \mathrm{~m}$ in areas of narrowing to $35 \mathrm{~m}$ in dilational areas [1]. The mine went into production in September 2007 and ranks sixth worldwide in silver production. It is the second largest silver mine in Peru and produced $263 \mathrm{t}$ of Ag in 2011 (8.77 Moz [2]). The aim of the present study is to examine the geological information that can be gathered from the chemical data collected during the exploration of the deposit. The data are made of 35 elements which were analysed from cores of the 52 boreholes interesecting the vein. Only reliable analytical data from the vein have been used: 17 elements $(A g$, 
As, $\mathrm{A} u, \mathrm{Ba}, \mathrm{Cd}, \mathrm{Co}, \mathrm{Cr}, \mathrm{Cu}, \mathrm{Hg}, \mathrm{Mo}, \mathrm{Ni}, \mathrm{P}, \mathrm{Pb}, \mathrm{S}, \mathrm{Sb}, \mathrm{Sr}, \mathrm{Zn}$ ) have been selected, and logarithm values are used.

Two issues are relevant to this study. The first one is whether the analyses can provide a realistic picture of the evolving geochemistry of the ore solutions. The second one is the interpretation of this scenario from a metallogenic point of view and its use to support exploration. To answer the first question, a geological analysis of the vein, as well as a Factor Analysis study of the chemical data have been carried out [3]. Results from both approaches are consistent with a major mineralizing episode tightly relating $\mathrm{Ag}, \mathrm{Au}, \mathrm{Pb}$, and $\mathrm{Sb}$ (F1: Factor 1), while $\mathrm{Zn}, \mathrm{Cd}$, and $\mathrm{Cu}$ (F2: Factor 2) show no relationship to the Ag grades. A discussion of the spatial distribution of Factor 1 metals shall help answer the second question.

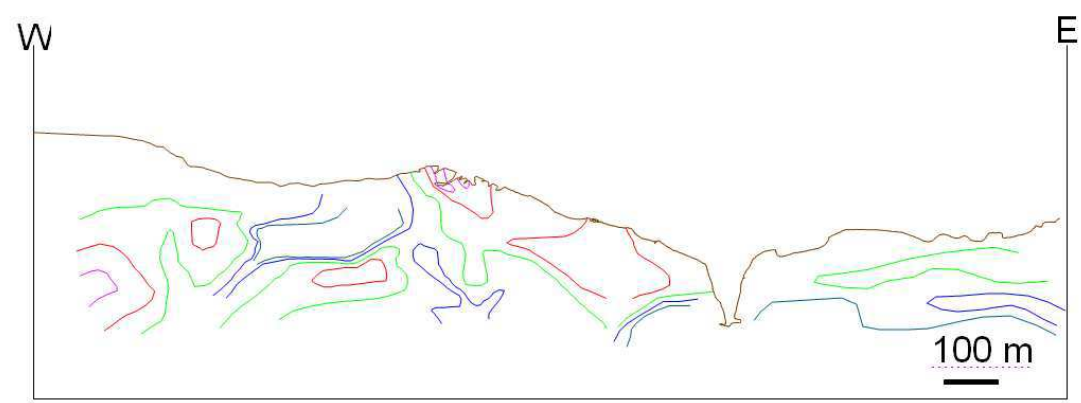

Fig. 1. Ag (logaritm of ppm) isocontent contours plotted on longitudinal section along the vein. Contour values: $2.2,2.4,2.6,2.8,3.0$.

\section{Element distribution in the vein}

The spatial distribution in the vein of selected $(\log )$ metal contents shows that the $\mathrm{Ag}$ grade (Fig. 1) is consistent with $\mathrm{Au}$ and $\mathrm{Pb}$ values, but not with $\mathrm{Zn}$ or $\mathrm{Cu}$ values. To explain this, a statistical analysis of all data has been carried out. Factor analysis, computed with the Programme R, defines two factors: F1, with loadings Ag: 0.875, Au: 0.896, Pb: 0.618, Sb: 0.855. F2, with loadings $\mathrm{Cu}: 0.603, \mathrm{Zn}: 0.723, \mathrm{Cd}: 0.808$, and S: 0.734. The spatial distribution of F1 (Fig. 2) is similar to that of $\mathrm{Ag}(\mathrm{Au})$ but differs from F2, suggesting unrelated events for $\mathrm{Ag}(\mathrm{Au})$ ores and for $\mathrm{Cu}, \mathrm{Zn}$ sulfides (chalcopyrite, sphalerite); even if the predictive value of these plots is limited, the conclusion is consistent with textural analysis of the ores (photomicrographs: [1, 3]).

\section{Metal Ratios, Flow Paths and Exploration}

Plotting ore metal distribution in a hydrothermal vein may show the flow paths of mineralisation, particularly if $(\log )$ metal ratios are used $[4,5]$. These plots are suggested to 
assist exploration $[5,6]$, since subtle changes in metal ratios may point

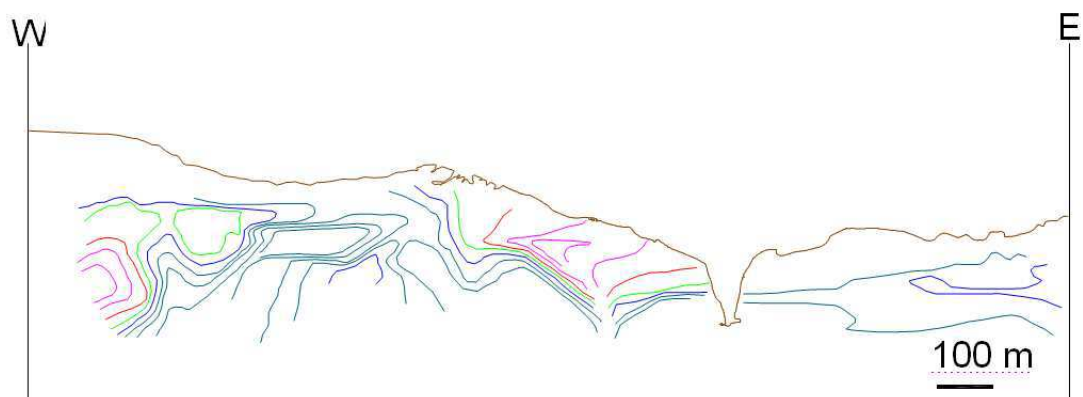

Fig. 2. Factor $1(\log )$ isovalue contours plotted on longitudinal section along the vein. Contour values: $-1.0 / 0.0,0.2,0.4,0.6,0.8-1$

to unknown metal concentrations. Fluid chemistry variations of the evolving hydrothermal system can be related to fluid flow, under the assumptions that (i) metal precipitation will not begin until saturation is attained; (ii) saturation and therefore precipitation will be enhanced by cooling, and this is favoured by flow of the fluids to shallower levels or by lateral flow away from the source; (iii) pressure drops or other changes related to this process may act in the same way; (iv) the temperature, and therefore the time, of precipitation of a particular metal depends not only on its solubility, but also on its concentration: the precipitation of a very diluted metal will be delayed, as compared with the saturated metal. Under these assumptions, the resulting scenario (Fig. 3 for $\log \mathrm{Ag} / \log \mathrm{Pb}$ ) suggests a consistent upward flow of the hydrothermal fluids, progressing from the center and from both sides of the structure -arrows- and selectively precipitating $\mathrm{Pb}$ at lower levels, with a relative $\mathrm{Ag}$ enrichment at higher levels, consistent with known models based on experimental data $[1,7]$.

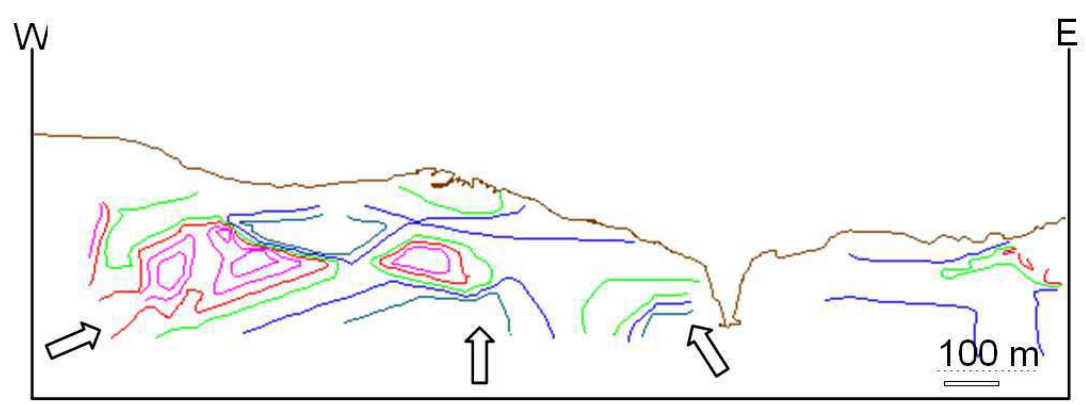

Fig. 3. Ratio $\log \mathrm{Ag} / \log \mathrm{Pb}$ isovalue contours plotted on longitudinal section along the vein. Contour values: $0.9,1.0,1.1,1.2,1.4$. (From chemical data in ppm).

The spatial distribution of the ore is also reflected by the $\log \mathrm{Ag} / \log \mathrm{Pb}$ ratio distribution (comp. Figs. $1 \& 3$ ). Au occurs as electrum or uytenbogaardtite, (Ag3AuS2), so it is tightly related to $\mathrm{Ag}$ [3], and $\log \mathrm{Au}$ grade and $\log \mathrm{Au} / \log \mathrm{Ag}$ ratio show the same 
distribution as $\log \mathrm{Ag}$ grade and $\log \mathrm{Ag} / \log \mathrm{Pb}$ ratio, respectively. The open loops in these log metal ratios suggests further ore to be expected in the lower center (possibly a Agimpoverished, Pb-enriched core, consistent with current ore petrological models [1, 7]); in addition Ag is suggested westwards at deeper locations.

\section{Conclusions}

Factor analysis of all the data is consistent with a main event of $\mathrm{Ag}$ deposition (Factor 1, Fig. 2), and fits with the space distribution of metal ratios -compare Figs. 1, 2, 3-, as well as with current metallogenetic models $[1,7]$. Overall geochemistry and fluid paths of the ore solutions are reflected by metal ratios (Fig. 3). The lower, open loop of the $\log \mathrm{Ag} / \log \mathrm{Pb}$ ratio distribution hints to a blind, deeper resource open for exploration.

Acknowledgments. The research was funded, as part of a MSc Thesis of the first author, by EU grant ALFA II-0459FA. The authors state their thankful recollection of Prof. Enrique Chacón († 2012), UPM, for his advice and discussion of statistical data. Facilities and authorization to publish by the Co. Minera Oro Vega S.A.C. are gratefully acknowledged. Laboratory work was carried out in the Lab ${ }^{\circ}$. Microscopía Aplicada $y$ Análisis de Imagen (rla 207) of the Madrid School of Mines, UPM: funding through the Lab_Network of the Comunidad de Madrid (code UP0644) and through projects GR920135 and CGL2006-13688-C02-01 is also acknowledged.

\section{References}

1. Gamarra-Urrunaga, J., Castroviejo, R., Bernhardt, H.J.: Preliminary Mineralogy and Ore Petrology of the Intermediate-Sulfidation Pallancata Deposit, Ayacucho, Peru. Canadian Mineralogist, 51, 67-91 (2013). DOI 10.3749/canmin.51.1.67.

2. The Silver Institute, http://www.silverinstitute.org/production.php.

3. Gamarra Urrunaga, J.: Caracterización mineralógica y geoquímica de la Veta Pallancata. Aplicaciones a la exploración minera, Parinacochas, Ayacucho, Peru. MSc Thesis, Red DESIR_Universidad Politécnica de Madrid, (2008).

4. Goodell, P.C., Petersen, U.: Julcani Mining District, Peru: a Study of Metal Ratios. Econ. Geology, 69, 347-361 (1974)

5. Castroviejo, R., Yparraguirre, J.A., Chacón, E.: Lithogeochemistry and Fuid Fow in the Eithermal Veta Rublo Bse Mtal-Slver Deposit, Chonta Mine (Huancavelica, Perú). In: Loredo, J. (ed.) Exploring our environment, Proc. 23rd IAGS, p. 159-160, Oviedo, Spain. (ISBN 97884-690-6461-0). (2007)

6. Petersen, U., Noble, D.C., Arenas, M.J., Goodell, P.C.: Geology of the Julcani Mining District, Peru. Econ. Geology, 72, 931-949 (1977):

7. Sack, R.O.: Internally consistent database for sulfides and sulfosalts in the system Ag2SCu2S-ZnS-FeS-Sb2S3-As2S3: Update. Geoch. Cosmochimica Acta, 69, 1157-1164 (2005). 